Post-print

Winter, J. S. (2008). "Emerging policy problems related to ubiquitous computing: Negotiating stakeholders' visions of the future." Knowledge, Technology \& Policy, 21, 191-203. doi:10.1007/s12130-008-9058-4.

\title{
Emerging Policy Problems Related to Ubiquitous Computing: Negotiating Stakeholders' Visions of the Future
}

Jenifer Sunrise Winter

\begin{abstract}
This paper provides an overview of the human-centered vision of Ubiquitous Computing and draws on research examining slowly emerging problems over a long-term time frame in the emerging Ubiquitous Computing environment. A six-phase process employing scenario planning, electronic focus groups, and problem assessment surveys harnessed the insight of 165 individuals from diverse backgrounds and regions throughout the State of Hawaii. Distinct differences were found between the problem identification of specialists (policymakers and systems designers) and non-specialists (everyday citizens), and there were significant differences found in the problem assessment between groups. The greatest differences in both phases emerged from social and psychological issues related to the emerging Ubiquitous Computing environment. It is argued that in addition to enormous technical changes, Ubiquitous Computing will serve to blur sociotechnical boundaries throughout the environment, challenging existing distinctions between humans and machine intelligences. As the potential for extending human capabilities via computing and communications technology is actualized in coming decades, what it means to be human will be a major source of public policy conflicts, and the early identification of problems related to these changes is essential in order to mitigate their impacts and socially negotiate a more desirable future.
\end{abstract}

\section{Mobile Communications and the Emerging Ubiquitous Computing Environment}

Advances in computing and communications technologies are leading to an environment in which a multitude of computer intelligences are present throughout our everyday lives. Rapidly decreasing size and cost of computer devices and the maturity of wireless networking are enabling a new computing paradigm characterized by a computational systems integrated into the everyday environment. Presently, numerous academic institutions, corporations, and government agencies are actively pursuing development of aspects of this Ubiquitous Computing environment.

We are quickly passing the point where the number of computers exceeds the number of humans on the planet and entering a many-to-one computer/human relationship (Siagri 2007). 
Post-print

Winter, J. S. (2008). "Emerging policy problems related to ubiquitous computing: Negotiating stakeholders' visions of the future." Knowledge, Technology \& Policy, 21, 191-203. doi:10.1007/s12130-008-9058-4.

Tennenhouse (2000) asserts that we will soon live in "a world in which networked computers

outnumber human beings by a hundred or thousand to one" (p. 43). This staggering ratio is one of the hallmarks that characterize the Ubiquitous Computing Era, expected to emerge by the year 2020 (Weiser \& Brown 1997). However, Ubiquitous Computing is not just about the omnipresence of computational systems. It represents new ways of thinking about humanmachine interaction.

Mark Weiser, Chief Technologist at Xerox PARC, offered a seminal vision of Ubiquitous Computing that was strongly user-centered and inspired by the realization that, even across the broadest spectrum of information and communication technologies, "the computer today is isolated from the overall situation... and fails to get out of the way of the work" (Weiser 1993, p. 76). This early vision emphasized the potential of multiple computers, in a variety of forms, to "enhance our peripheral reach" without creating information overload.

In 1997, nearly a decade after the first Ubiquitous Computing research was initiated, Weiser and Brown observed that we were currently in a transitional period that was expected to act as a catalyst that moves us into the Ubiquitous Computing Era, where a multitude of will computational systems will be embedded in the everyday environment. A present manifestation of this trend is the widespread diffusion of mobile phones. At the end of 2007, there were an estimated 3.25 billion cellular phone accounts worldwide (Ridley 2007), many of these supporting high speed data transmission, video services, and mobile devices with powerful computational ability. Although these mobile devices are not necessarily manifestations of Ubiquitous Computing, there are examples, such as Japan's Yaoyorozu ("Eight Million Gods") Project in which mobile devices, coupled with radio frequency identification tags (RFID) 
Post-print

Winter, J. S. (2008). "Emerging policy problems related to ubiquitous computing: Negotiating stakeholders' visions of the future." Knowledge, Technology \& Policy, 21, 191-203. doi:10.1007/s12130-008-9058-4. demonstrate that Ubiquitous Computing is already present in some form. ${ }^{1}$ Bell and Dourish

(2006) have noted that Ubiquitous Computing literature tends to focus on the "proximate future", visions of "potential future computational worlds" (p.133), and they note that Weiser's original vision still frames the majority of Ubiquitous Computing research, despite radical changes in information technology and implementation over the past several decades. Instead, they focus on the many ways in which Ubiquitous Computing is already manifest as part of messy, sociotechnical systems and note that research should focus on understanding present manifestations of Ubiquitous Computing. ${ }^{2}$ This new orientation breaks down artificial distinctions between the technical and the social, arguing that user interaction with systems is always situated (Dourish, 2001; see also Suchman, 1987).

Ubiquitous Computing research has focused on building an environment in which computers allow humans to focus attention on select aspects of the environment and operate in supervisory and policy-making roles. Ubiquitous Computing emphasizes the creation of a human-computer interface that can interpret and support a user's intentions. For example, MIT's Project Oxygen seeks to create a system in which computation is as pervasive as air:

In the future, computation will be human-centered. It will be freely available everywhere, like batteries and power sockets, or oxygen in the air we breathe... We will not need to carry our own devices around with us. Instead, configurable generic devices, either handheld or embedded in the environment, will bring computation to us, whenever we need it and wherever we might be. As we interact with these "anonymous" devices, they will adopt our information personalities. They will respect our desires for privacy and security. We won't have to type, click, or learn new computer jargon. Instead, we'll communicate naturally, using speech and gestures that describe our intent ... (Massachusetts Institute of Technology 2004).

\footnotetext{
${ }^{1}$ This project is associated with the national ICT plan called u-Japan "Ubiquitous Japan" that seeks to achieve the ubiquitous information society by 2010. The term Yaoyorozu refers to the "eight million gods" or intelligences found in nature as described in the Shinto religion and is used as a metaphor for the ubiquitous society (http://www.8mg.jp/).

${ }^{2}$ It should be noted that policy and planning activities are inherently futures-oriented and that the many ways in which the future it might develop, must remain in focus.
} 
Post-print

Winter, J. S. (2008). "Emerging policy problems related to ubiquitous computing: Negotiating stakeholders' visions of the future." Knowledge, Technology \& Policy, 21, 191-203. doi:10.1007/s12130-008-9058-4.

This is a fundamental transition that does not seek to escape the physical world and "enter some

metallic, gigabyte-infested cyberspace" but rather brings computers and communications to us, making them "synonymous with the useful tasks they perform" (Dertouzos 1999, p. 52). Thus Ubiquitous Computing does not seek to escape the real world, but augment it by integrating information displays in the physical realm.

This observation highlights a distinction between several views about the Ubiquitous Computing environment. Some, (e.g., Cerf 1999) describe a future environment populated by automated versions of everyday things, such as refrigerators, and even birds. From this perspective, the future appears as a recast of the existing physical world (complete with a variety of automated assistants). In contrast, Weiser's Ubiquitous Computing vision places orientation on the user. Instead of having computers perform tasks for you, the physical environment will be activated, and it will seem like the computational intelligence is merely an extension of oneself. Ubiquitous Computing research is increasingly focusing on specific interaction contexts and on software intelligence that augments individual capabilities (e.g., Maes, 1999; Abowd, Ebling, Hunt, Lei, \& Gellersen 2002; Starner 2003). In the future, the Ubiquitous Computing environment may integrate the 'real' and 'virtual' worlds and create a reality fundamentally different-in-kind than anything we can currently imagine.

In addition to everyday appliances with embedded computers, we are also seeing the emergence of many tiny devices that are not typically thought of as computers. Sensors and actuators are small computational devices that are spread throughout the physical environment, gathering data and performing control functions. The cost of these devices is dropping dramatically due to new technologies and economies of scale; while wireless connectivity will allow both a smaller form factor and the ability to be intermittent, rather than always on. One 
Post-print

Winter, J. S. (2008). "Emerging policy problems related to ubiquitous computing: Negotiating stakeholders' visions of the future." Knowledge, Technology \& Policy, 21, 191-203. doi:10.1007/s12130-008-9058-4. promising development is a new type of silicon-based sensor called MEMS

(microelectromechanical systems) that is emerging as a key foundation for embedded systems requiring computation, sensing and control. MEMS sensors are already employed in automobile airbag systems, and their use in applications requiring sensing light levels, chemical or magnetic fields is growing. Capabilities for ongoing, detailed data collection from a wide variety of sources will be enhanced. For example, Zambonelli, Gleizes, Mamei, and Tolksdorf (2005) describe the development of "spray computers", clouds of self-organizing MEMS sensors that might be sprayed into an environment and "will soon pervade ICT scenarios at every scale and at every level" (p. 2). Other real-life applications might involve sensors placed for environmental control systems in homes, self-repairing materials, or furniture that responds to items placed on it. The employment of networked sensors will provide opportunity for an endless variety of services.

\section{Social and Psychological Aspects of Ubiquitous Computing}

The social and psychological aspects of human-computer interaction also pose interesting challenges. Increasingly, computers are being recognized as persuasive technologies, possessing the ability to alter human attitudes, beliefs, and behaviors (e.g., Fogg 1998; Tscheligi \& Reitberger 2007). Nass et al. (1995) were early proponents of the idea that interaction between humans and computers is essentially social and that rules normally reserved for human social behavior are transferred to human-computer interaction. Even "minimal" social cues are sufficient to generate behaviors and attitudes toward computers that are typically seen in human-human interaction, and users can be induced to treat computers as if they were human, even though they understand that computers do not actually possess human motivations or "selves". Human social responses to computers are not the result of psychological or social 
Post-print

Winter, J. S. (2008). "Emerging policy problems related to ubiquitous computing: Negotiating stakeholders' visions of the future." Knowledge, Technology \& Policy, 21, 191-203. doi:10.1007/s12130-008-9058-4. abnormalities, but are part of normal interaction between humans and computers. Thus,

researchers are increasingly exploring the social and emotional aspects of human-computer interaction (e.g., Picard, Wexelblat, \& Nass 2002; Bickmore \& Picard 2005). Ultimately, Ubiquitous Computing systems will challenge the boundaries between human and machine and challenge us to reassess what it means to be human.

A growing body of literature addresses the proliferation and sophistication of mobile phones, and social scientists are now recognizing them as significant sociocultural artifacts. There are already a number of examples Ubiquitous Computing via mobile phone infrastructure in countries such as South Korea and Singapore (Bell \& Dourish, 2006). Mobile phones are being increasingly recognized as flexible computational artifacts. These devices are not only technical, as their development is formed by numerous social, political, or economic interactions that have the potential to radically transform virtually every aspect of human life. Castells, Fernández-Ardèvol, Qiu, and Sey (2006) have traced the development of the "mobile network society" by examining the global diffusion of mobile networks and network logic. Ling (2004) has conducted extensive ethnographic research elucidating how mobile communications devices have penetrated, and transformed, virtually every aspect of human social life. Bell (2006) has also taken an ethnographic approach, examining the relationship between mobile devices and social identity and roles in Asia. She describes mobile networks as "constellations of social and cultural practice" (p.54). Katz (2006a; 2006b) has focused extensively on the social and spiritual aspects of mobile phones and has identified these aspects as major frontiers for mobile scholarship. Glotz and Bertschi (2006) conducted a Delphi study to explore near-term impacts of mobile phones, identifying "privacy, stress, and distraction" as 
Post-print

Winter, J. S. (2008). "Emerging policy problems related to ubiquitous computing: Negotiating stakeholders' visions of the future." Knowledge, Technology \& Policy, 21, 191-203. doi:10.1007/s12130-008-9058-4. major challenges (p. 86). While these problems are already recognized, we can anticipate in the

future that they will be exacerbated and perhaps take on new forms of concern to users.

As the environment around us becomes increasingly active and everyday things are imbued with computational abilities, the potential for extending human capabilities via computing technology will present myriad opportunities and challenges. Increasing attention has been placed on the need for everyday citizens to be more actively involved in technology policy (e.g., Sclove 1995; Winter 2006). Policy and planning activities involving subjective judgments often rely on probability or level estimates by experts in a specific domain. The process of expert selection has been questioned on grounds that it is not easy to select a large number of qualified participants, or even to identify who these experts may be. More importantly, experts in a given area may have difficulty viewing a problem holistically, as they tend to be self-selecting and to share common frames of reference. In addition to the inclusion of interdisciplinary panels of specialists, increasing recognition of the need to widen input into the policy and planning process has led to development of participatory methods that include members of the general public. Glenn (1994) observes that "planners are often out of touch with the feelings of the people" (p. 3). Technology policies are often framed by representatives of three groups: businesses, the military, and universities (Sclove 1996). It is members of these groups who are "invited to testify at congressional hearings, serve on government advisory panels, and prepare influential policy studies" (p. 2). While the public at large is deeply impacted by these developments, and may have alternate opinions or concerns, these viewpoints are not directly included in this debate. Dator (1996) argues that "foresight that is undertaken as only a technical, scientific, and professional matter is incomplete. Foresight must also and necessarily be a political, ethical, esthetic and very broadly participatory project... It is 
Post-print

Winter, J. S. (2008). "Emerging policy problems related to ubiquitous computing: Negotiating stakeholders' visions of the future." Knowledge, Technology \& Policy, 21, 191-203. doi:10.1007/s12130-008-9058-4. absolutely essential that all people who have a stake in the future be involved in determining it"

(p. 111). While the level of detail and expertise required in implementing plans is far more complex than can be handled as a public process, inclusion of the public can set criteria for planning that can be used as guidelines by decision makers (Glenn 1994).

One of the more successful efforts towards public participation is the Consensus Conference method used in discussion of technology policy in Denmark (Andersen \& Jaeger 1999). This technique involves selecting a citizen panel that interacts with technology experts on a given subject. The citizen panel assesses the technology and its potential consequences, both positive and negative, and drafts a summary report for public consideration. This process stimulates public debate, as well as informs politicians and planners about the thoughts of the public. However, in a recent study of members' efforts towards e-democracy, the OECD determined that active citizen participation was still rare (Organisation for Economic Cooperation and Development 2003).

\section{Ubiquitous Computing in Hawaii}

The present research investigated slowly emerging problems related to the emerging Ubiquitous Computing environment in the State of Hawaii. One hundred and sixty-five individuals from throughout the State engaged in a multi-phase study seeking to identify, describe, and assess the importance of, emerging problems related to the emerging Ubiquitous Computing environment. In order to harness the views of everyday citizens, two groups, technology specialists (including local and state officials involved in technology policy and systems designers) and non-specialists participated in a multi-phase process employing scenario planning, electronic focus groups, and problem assessment surveys. 
Post-print

Winter, J. S. (2008). "Emerging policy problems related to ubiquitous computing: Negotiating stakeholders' visions of the future." Knowledge, Technology \& Policy, 21, 191-203. doi:10.1007/s12130-008-9058-4.

Candidates for the specialists group were identified through affiliation with the Hawaii

Technology Trade Association (HTTA), a statewide, private-sector organization that works to support Hawaii’s technology industry. HTTA has several hundred members representing numerous technology sectors, including information technology, telecommunications, software, and biotechnology. Invitees for the non-specialists group were intended to reflect the diverse demographics of Hawaii residents. A local civic group whose members represent the diversity of Hawaii was used as a means to locate participants for this group. The Chamber of Commerce of Hawaii and its affiliate chapters were selected because they represent a variety of organizations and individuals throughout the state, including small businesses, large corporations, state and federal government, and the military. Members come from a wide variety of socio-economic backgrounds and represent a variety of ages, genders, and cultural backgrounds. Furthermore, these individuals take an active interest in the social and economic welfare of the community.

In phase one, a future scenario was created as a stimulus for the focus group participation. A scenario is an imaginary environment or sequence of events, one of an infinite number of "stories" that can be told about possible alternative futures. It should be noted that a scenario is not a forecast, and it is not intended to be treated as one. Presenting it to the reader as such may distort his or her perception of the probability of certain events. A scenario can be used to support forecasts and to stimulate thought and debate about unacceptable or desirable futures by encouraging individuals to think about a future state as if it were already present. "Thinking through these stories, and talking in depth about their implications, brings each person's unspoken assumptions about the future to the surface" (Schwartz 1991, xv). The purpose of this was to displace each person, so far as possible, from his or her present-focused 
Post-print

Winter, J. S. (2008). "Emerging policy problems related to ubiquitous computing: Negotiating stakeholders' visions of the future." Knowledge, Technology \& Policy, 21, 191-203. doi:10.1007/s12130-008-9058-4. mindset so that their own assumptions about the future could be articulated. The data-based

scenario used in this study was developed using both qualitative and quantitative inputs. A significant source was the existing literature describing visions of the Ubiquitous Computing environment, including existing forecasts of ICT development. Quantitative data, such as demographic and economic trend data within the state, were also considered. The final scenario integrated social, political, economic, technical, educational, and psychological dimensions and presented an integrated vision of Hawaii in the year 2022. ${ }^{3}$ The final scenario was implemented in the electronic focus groups.

The purpose of the electronic focus groups in this study was to generate an extensive list of problems (stimulated by the scenario) relating to Ubiquitous Computing in the State of Hawaii over an extended time frame. The process of idea generation (i.e., problem elicitation) or "brainstorming" is a computer-mediated communication (CMC) structure intended to generate large numbers of ideas. The questions posed in the focus group addressed a variety of domains ensuring a more holistic analysis of potential future trends or events. These categories were intended to be broad and to act as guides for eliciting a comprehensive list of problems associated with Ubiquitous Computing in Hawaii. The six categories were the same as those used to create the scenario and each was accompanied by a brief textual description to guide the participants. $^{4}$

\footnotetext{
${ }^{3}$ To address issues of content and consistency, the draft was first read by two Ph.D. candidates and three experts in related areas. The content of the scenario was revised several times based on this feedback, and category headings were removed in order to make the narrative flow more smoothly and to reduce the length of the document. The revised scenario was then read by 29 undergraduate students and two non-students (representing non-specialists), and four graduate students and three Ph.D. holders in related areas (representing specialists). Feedback from the non-specialists addressed factors such as readability and ease of comprehension.

${ }^{4}$ The electronic focus groups underwent a series of pretests involving 29 undergraduate students and two nonstudents (representing non-specialists) and five graduate students and two Ph.D. holders in related fields
} 
Post-print

Winter, J. S. (2008). "Emerging policy problems related to ubiquitous computing: Negotiating stakeholders' visions of the future." Knowledge, Technology \& Policy, 21, 191-203. doi:10.1007/s12130-008-9058-4.

The goal for this phase was to select a representative panel from each group. To ensure

that a broad spectrum of views would be included in the focus groups, a form of quota selection was used to identify invitees Candidates were selected so that there was balance between disciplines, geographical location, and gender. ${ }^{5}$ Nineteen members of each group participated in the electronic focus groups via an online conferencing system. Based on the recommendations of Salmon (2000) and feedback from the pretests, the conference was scheduled to last for 3.5 weeks. During this phase, the moderator monitored both group discussions for areas that were not very active or issues that required elaboration. During the focus groups, participants were asked to reflect on a scenario for the year 2022 of a fully immersive Ubiquitous Computing environment. To elicit a broad range of responses, each participant was asked to generate descriptions of potential problems that they felt may emerge in each of six domains (social, political, economic, technical, educational, and psychological). Where imbalances of participation were detected, the moderator prompted participants to contribute additional insights. Individuals were instructed to read and elaborate on others' inputs and to add their own problem statements. However, they were also reminded that the goal was to generate as many problem statements as possible and that criticism or rejection of others' statements was not appropriate at this stage.

Due to the exploratory nature of the research and because the specific variables were not yet identified, the process of problem extraction was well-suited to the qualitative research paradigm as described by Creswell (1998). Representative problem statements were selected from the transcripts via content analysis. As defined by Stone, Dunphy \& Bernstein (1966),

(representing specialists). These were conducted to assess: system compatibility and reliability, usability, clarity of instructions, and success in eliciting responses.

${ }^{5}$ The list was also monitored to account for ethnicity and government and private industry where possible. 
Post-print

Winter, J. S. (2008). "Emerging policy problems related to ubiquitous computing: Negotiating stakeholders' visions of the future." Knowledge, Technology \& Policy, 21, 191-203. doi:10.1007/s12130-008-9058-4. content analysis describes "any research technique for making inferences by systematically and

objectively identifying specified characteristics within text" (p. 5). Specifically, this process employed a form of content analysis called conceptual analysis, or thematic analysis, that is intended to establish the existence and frequency of concepts within a text (Stone 1997). Because it was anticipated that many of the statements would describe issues that were not yet identified, no pre-conceived categories were used. At this point, the researcher was primarily concerned with identifying the existence, rather than the frequency, of concepts. ${ }^{6}$

The level of analysis selected was "problem statement" and the focus of conceptual analysis was the identification of both explicit and implicit concepts that represented "problems" to one or more individuals. It should be observed that the participants were directed to generate statements of problems, and the majority of comments did so explicitly. However, implicit problem statements also emerged in the elaborations, and many posting described problems at great length or contained multiple problem statements.

The transcripts were carefully reviewed by several coders and both explicit and implicit statements were highlighted within the text. After the initial problem statements were identified in the transcripts, a highly qualified and critical reviewer with credentials and academic background similar to the researcher was asked to go through an unmarked version of the transcripts and do the same. A high degree of cross-validation between the supported the assertion that as many problems as possible had been identified in the transcripts.

The process of statement extraction was based on immersion in the complete transcripts of both groups and repeated coding of problem statements. This process led to the emergence

${ }^{6}$ Following Molitor (1977), it might be inferred that frequency of problem elicitation indicates that a problem is already somewhat mature and has already been considered. While frequency was not a concern at this point, it was recorded for later analysis. 
Post-print

Winter, J. S. (2008). "Emerging policy problems related to ubiquitous computing: Negotiating stakeholders' visions of the future." Knowledge, Technology \& Policy, 21, 191-203. doi:10.1007/s12130-008-9058-4. of a number of problem categories. A classification of the major issues (problems) presented

was developed and these categories were refined and provided with textual descriptions that were drawn, as much as possible, from the original text. The categories were examined repeatedly and related concepts were combined to form broader categories where possible. The transcripts were reviewed until no new categories were identifiable and each posting had been linked to one or more of the problem statements. In order to confirm that the problem statements accurately reflected the original text, the researcher confirmed that each was linked to one or more comments. A second coder was then asked to examine each of the problem statements and the corresponding textual passage(s) from the transcripts to assess whether the statements were clear and accurately represented the meaning of the original text. ${ }^{7}$ Several statements were revised, clarified or combined based on this assessment.

The revised list of 80 problem statements derived from this qualitative process was implemented in the problem assessment phase of this research. Following the theoretical position that problems are socially-defined phenomena (e.g., Union of International Associations 2001), and acknowledging that "images of the future" (Polak 1961; Bell 1996b) actively shape its development, this phase also sought to determine whether differences in problem assessment existed between the two groups. The 80 problem statements generated in the electronic focus groups were arranged by domain and placed on an electronic questionnaire. Problem statements from both the specialists and non-specialists were combined. ${ }^{8}$ Participants were asked to rate the items in each section statement on a Likert-type scale of 0 to $4(0=$

\footnotetext{
7 The two individuals selected for these tasks were Ph.D. candidates in the information sciences who were selected because of similarity of background to the researcher and because they were known to be detail-oriented and critical thinkers. A third individual repeated the complete process.

${ }^{8}$ The specialists and non-specialists were not aware of each other's participation in any phase of this research. Each group was told that "a group of your peers from throughout Hawaii" had generated the problem statements and all participants viewed the complete list of statements. This cross-pollination was intended to share ideas between groups while eliminating the potential for one group over- or under-valuing the other's contributions.
} 
Post-print

Winter, J. S. (2008). "Emerging policy problems related to ubiquitous computing: Negotiating stakeholders' visions of the future." Knowledge, Technology \& Policy, 21, 191-203. doi:10.1007/s12130-008-9058-4. relatively unimportant compared to the rest, $2=$ moderately important compared to the rest, and

4 = extremely important compared to the rest).

Two new sets of participants representing the specialists and non-specialists participated in this phase. The mean score for each problem statement was calculated for specialists and non-specialists, and an aggregate score (weighted average of both groups) was produced for each item. Separate groups of specialists and non-specialists then assessed each of the problem statements to determine its perceived importance (by each group and as an aggregate total). Goals of this research included identification and assessment of slowly emerging problems related to Ubiquitous Computing and also an examination of differences between those typically involved in technology decision-making and policy formation (specialists) and members of the general population.

\section{Differences between Specialists and Non-specialists}

In the focus groups, specialists and non-specialists expressed distinct and different concerns. ${ }^{9}$ Many of the specialist responses accepted the vision of Ubiquitous Computing in the year 2022 as a natural, and even desirable, progression of technology. In fact, many of the "problems" they identified dealt with current or near-term barriers to arriving at the full Ubiquitous Computing environment, primarily in the Technical, Economic and Political domains (e.g., the need for economic diversification to support high-technology industries within Hawaii). This was not surprising, as this group was comprised of technical experts and policy-makers, those typically involved in technological development within the State. Nonspecialists, in contrast, adopted a more critical perspective, with a number observing that they

\footnotetext{
${ }^{9}$ During this study, neither group was aware of the others' existence.
} 
Post-print

Winter, J. S. (2008). "Emerging policy problems related to ubiquitous computing: Negotiating stakeholders' visions of the future." Knowledge, Technology \& Policy, 21, 191-203. doi:10.1007/s12130-008-9058-4. found the very idea of Ubiquitous Computing invasive or otherwise threatening. One nonspecialist participant observed that "Rather than being about communication the scenario that I am in is one of my worst nightmares... This scenario seems to put barriers between all of the things that make us sure that we are human."

The Psychological domain proved a rich source of problem statements related to privacy and surveillance, human species identity, self-identity, autonomy, and the boundary between human and machine intelligences. It was also the point of greatest divergence between the specialist and non-specialist participants in the study, revealing the non-specialists' tendency to elaborate more human-centered, or personal, concerns. Of the fourteen unique Psychological statements derived from the focus groups, eight (57\%) were generated by the non-specialist group, with three (21.5\%) from the specialists and the remaining three $(21.5 \%)$ independently generated by members of both groups. A complete list of statements generated for the Psychological domain is included in Table 1.

Furthermore, in the problem assessment phase, there were significant differences between participants from each group $(\mathrm{N} 1=58$ and $\mathrm{N} 2=63)$ when asked to assess each problem's severity on a five-point scale ( 0 to 4$)$. By the Mann-Whitney U test, ten of the fourteen items (71\%) in the Psychological domain showed significant differences (two-tailed, $p \leq .05$ ), in each case the non-specialists assessing problem statements as more important than the specialists (see Table 2 and Figure 1).

Within this domain, several problem statements addressed issues of privacy and surveillance in the emerging Ubiquitous Computing environment. One problem statement suggested that $[t]$ he pervasiveness of miniature surveillance devices present throughout the environment will prevent the average person from knowing what kind of personal data is being 
Post-print

Winter, J. S. (2008). "Emerging policy problems related to ubiquitous computing: Negotiating stakeholders' visions of the future." Knowledge, Technology \& Policy, 21, 191-203. doi:10.1007/s12130-008-9058-4. collected and with whom it is being shared $(U=1641, p=.189)$. This concern also extended to the possibility that [i]nvasive use of technology enabling physical detection of human emotion or higher level thought processes will result in an invasion of privacy $(U=1431, p=.017)$. Participants also suggested that [m]any people will become more guarded or "disconnected" as a way of self-preservation due to pervasive surveillance devices ( $U=1765, p=.643)$. Concerns about electronic surveillance and privacy are already well established and are likely to be exacerbated by Ubiquitous Computing: we may have thousands of interconnected computers scanning the environment and collecting and communicating personal information about our activities to government agencies, corporations, or other individuals. With the pervasiveness of miniature surveillance devices there may be virtually no aspect of human life that remains private. As it becomes increasingly difficult to prevent the average person from knowing what kind of personal data is being collected and with whom it is being shared, greater psychological stress or illness may occur. It is also no surprise that privacy-related statements shared greater consensus between groups, as concern about privacy in the Ubiquitous Computing environment are already well established and widely discussed (International Telecommunication Union 2005).

A related concept expressed the concern that $[d]$ ue to technology-mediated communication and electronic surveillance it will be increasingly difficult to establish strong individual identities ( $U=1153, p=.000$ ). This begins to touch on issues of human identity, autonomy, and the conflict (or transcendence) of the boundaries between human and machine intelligences, further elaborated in the following statements:

Autonomous, intelligent computers will operate on our behalf without adequate human oversight $(U=1460.5, p=.027)$; 
Post-print

Winter, J. S. (2008). "Emerging policy problems related to ubiquitous computing: Negotiating stakeholders' visions of the future." Knowledge, Technology \& Policy, 21, 191-203. doi:10.1007/s12130-008-9058-4.

There will be a lack of personal accountability and responsibility for one's actions due to increased automation and/or biological or mechanical augmentation of humans $(U=1363.5$, $p=.010)$;

Intelligent computers and/or biological enhancements will anticipate our choices or become part of us, making it difficult to live spontaneously and have free will $(U=1235.5, p=.001)$; and

Psychological tension will arise due to individuals' inability to distinguish between human and computer interactions (e.g. some computers may appear so intelligent that it is difficult to tell the difference) $(U=1260.5, p=.010)$.

Ubiquitous Computing has been anticipated as an extension of one's own intelligence into the environment. While many people eagerly anticipate these augmentations, the development of such systems must be carefully mediated so that users maintain a sense of personal control.

One non-specialist participant questioned the rationale for biotechnical advancements:

Perhaps I am already out of date but why would one choose to allow computers to control human functions? This question is important on both a personal and a group scale... Why would anyone choose to be less human except perhaps the terminally ill who might be desperate to continue living. Why would anyone want to live to 120 unless they could enjoy their work, friends, family and community interaction?

Another theme that emerged from the focus groups was related to issues of human (species) identity and the sacredness human of life. One statement that addressed this concern was: With cloning, the concern for the welfare of artificial life, and the quest for extending life beyond natural limits, there will be less emphasis on spirituality or the sacredness of life $(U=1161.5, p=.000)$. This distinction between human and "other" was also noted in the statement, [s]ome people will become "less than human" due to biological or mechanical enhancements $(U=1327, p=.005)$. Several non-specialists elaborated this concern:

In our quest to purchase the perfect body that is disease-free, is there equal motivation to develop our spiritual selves? Life is sacred, but with cloning, the concern for the welfare of artificial life, the quest for extending life beyond what was intended, it is difficult to assume there will be much emphasis on the sacredness of life. That must always be balanced with 
Post-print

Winter, J. S. (2008). "Emerging policy problems related to ubiquitous computing: Negotiating stakeholders' visions of the future." Knowledge, Technology \& Policy, 21, 191-203. doi:10.1007/s12130-008-9058-4. growing technology; and

If no one is responsible for themselves or others will the human race survive? Will a hybrid race evolve? And what happens to the thoughts and feelings, the spirituality that requires ethical conduct?

A problem statement from the Technical domain addressed a related concept: Human biological performance will need to be adjusted via genetic modification to keep up with technological and societal problems (i.e. natural evolution will be too slow) $(U=1452.5$, $p=.022$ ), also dealt with human boundaries and identity. "[T]ransgenics and other methods of genetic modification will be essential to reach a state of equilibrium with the technical advances", observed one focus group participant.

The idea that technology is altering, or defiling, the sacredness of human life is clearly a perception shaped by diverse cultural or religious views. While some people may consider such concerns to be trivial or non-problematic, these are not views that can be ignored. Kurzweil (1999) writes:

Before the next century is over, human beings will no longer be the most intelligent or capable type of entity on the planet. Actually, let me take that back. The truth of that last statement depends on how we define human. And here we see one profound difference between these two centuries: The primary political and philosophical issue of the next century will be the definition of who we are [italics mine] (p. 2).

\section{Emerging Policy Problems: Control of Technology and Self}

Outside the electoral process or feedback after implementation, members of the general population are typically alienated from the process of technology policy development (Sclove 1995; Winter 2006). Substantial differences in opinion between the specialist and non-specialist groups and the discovery that both groups found non-specialists concerns to be valuable contribution, supports the need for a more participatory approach to decision making about technology. These issues related to public involvement were examined in light of Risk Society 
Post-print

Winter, J. S. (2008). "Emerging policy problems related to ubiquitous computing: Negotiating stakeholders' visions of the future." Knowledge, Technology \& Policy, 21, 191-203. doi:10.1007/s12130-008-9058-4. theories, which suggest that modern society is characterized by risk, a systematic method of handling the various threats introduced by the advance of technologies (Beck 1998). The Industrial Age marked a transition from risks imposed by external forces to ones that are willfully initiated by humans in order to attain technological progress. "The greater the threat (or to be more precise, the social definition and construction of the threat)... the greater the change which has to be undertaken to control the future... As scientific knowledge opens up new opportunities for us, it also makes the world more complex and unknowable" (Beck 1998, pp.11-12).

In this context, problems such as global warming or pollution are not merely environmental but institutional and embedded in technocratic processes that place little value on public opinion or concern. While scholarship has focused primarily on factors such as environmental pollution or other health hazards, there are also risks related to the advent of medical biotechnology or machine-human hybrids, the "technical advances [that] affect our very makeup as human beings" (Giddens 1990, p. 170). However, another type of risk can be seen in problem statements that address physical changes in human evolution, as well as human-machine interactions that stretch the boundaries of human identity. Here, the human body, psyche, or species identity - rather than the external environment - is transformed, or assailed. These risks are characterized by internal forces, rather than external ones. While this emerging class of risks is anticipated to affect large numbers of people, the impact may be more personal; thus these problems may be characterized by greater divergence in opinion than external risks.

As scientific knowledge and the opinions of experts are questioned, modern society becomes much more reflexive, aware that it is founded upon knowledge that is continually 
Post-print

Winter, J. S. (2008). "Emerging policy problems related to ubiquitous computing: Negotiating stakeholders' visions of the future." Knowledge, Technology \& Policy, 21, 191-203. doi:10.1007/s12130-008-9058-4. revised. Giddens describes this modern situation as a "juggernaut" or "runaway world"

(Giddens 1990, p. 151). To minimize the high-consequence risk brought about by this process, he advocates harnessing the positive aspects this process, particularly "envision[ing] alternative futures whose very propagation might help them be realized" (Giddens 1990, p. 154).

\section{Slowly Emerging Problems and the Need for Participatory Foresight}

From a perspective focused on the present, or the short-term future, problems often seem to appear suddenly. However, while there are "singularities" that may be completely resistant to foresight activities, the vast majority of future developments do provide some advance warning (Renfro 1994, p. 12). Public policy problems are often "preceded by long shadows, long trains of activity", emerging slowly, over decades or even the course of a century (Molitor 1977, p. 6). There is a need for a long-term view to guide policy decision making, as this will assist in identifying long-term problems or opportunities related to the Ubiquitous Computing environment. This information can reduce uncertainty and guide the decisions of both policymakers and those directly involved in system development (Wedemeyer, Ono \& Winter 2001).

One important consideration is the degree to which different opinions form around a single problem. Some issues may have strong consensus about their importance, even if there are great differences in opinion regarding the cause or solution. For example, few people will differ in their assessment of a highly tangible problem with physical impact such as terrorists using new weapons of mass destruction to destroy human life. However, another class of problems exists that is more prone to disagreement. The problem statements outlined above that address the future evolution of the human species or challenges to identity have clear 
Post-print

Winter, J. S. (2008). "Emerging policy problems related to ubiquitous computing: Negotiating stakeholders' visions of the future." Knowledge, Technology \& Policy, 21, 191-203. doi:10.1007/s12130-008-9058-4. cultural or religious implications and are likely to have greater variance in opinion about them.

The very definition of problem indicates that at least two different views form around it, and it is expected that no problem will ever achieve complete consensus. In particular, emerging problems may have multiple perspectives and a high degree of polarization. That is, some individuals may find a particular statement about the future to be a critical issue while others may deem it absurd or unworthy of attention. However, as long as they are perceived as significant to some members of society, they may create additional problems (e.g., psychological stress, political unrest).

Any information that we may have about these issues is important, as it tells us what we do not already know. Jim Dator, former President of the World Futures Studies Federation, has observed that "Any useful statement about the future should appear to be ridiculous and to elicit responses of disbelief, shock, horror, or disgust. If you nod your head in agreement about some statement about the future, then forget it. It may be true, but it is not particularly useful to you" (Dator 1997, p. 2). Pinpointing future problems that lack consensus is especially useful because these are characterized by a high degree of uncertainty. Early identification and isolation of emerging issues with high uncertainty but potentially large impacts is of immense use to planners and policymakers, as it highlights areas where small actions in the present may yield a high social and economic return on investment in the future.

The inclusion of both specialist and non-specialist groups enhance the information generated and thus the decision-making process. A primary contribution of this research is the identification of specific differences between specialist and non-specialist participants in the perception and significance of problems related to the Ubiquitous Computing environment as it might develop in the future. Examination of these differences is important because it initiates 
Post-print

Winter, J. S. (2008). "Emerging policy problems related to ubiquitous computing: Negotiating stakeholders' visions of the future." Knowledge, Technology \& Policy, 21, 191-203. doi:10.1007/s12130-008-9058-4. future-oriented social negotiation involving multiple perspectives, leading to a more humancentered implementation of technology. In addition to reducing the separation of the planning process and the public, including both groups adds legitimacy to future planning efforts. Nonspecialists have less direct involvement in the development of technologies and technology policy; however, they are important stakeholders who are profoundly affected by the outcomes of this process. While both groups are part of the processes of sociotechnical system development, non-specialists are less active; they may find the creation and critique of technical systems to be out of reach or overwhelming. This study indicated that non-specialists participating in the electronic focus groups did express distinct and different concerns than specialists. The non-specialists expressed greatest concern for the Psychological domain and human-centered problems, while specialists were identified as being more system-centered, generating more statements related to the Political domain and other factors related to economic growth. Importantly, analysis revealed that both groups found the problem statements generated by non-specialists to be valuable contributions, arguing for their inclusion in the process of problem identification.

Policymaking and planning are inherently future-oriented activities, and the content contributions noted above provide valuable information upon which current policymakers and system designers can base their decisions. As Helmer (1983) observes, emphasis should be on identification of key "branching points" that may suggest where early policy intervention may be successful. This research assists in identification of those areas that most require attention, indicating priorities where policy intervention would be useful or necessary, or highlighting areas for monitoring and further evaluation. Emerging problems must not be discounted in favor of the present. These often appear to be less urgent or ill-defined; however these potential 
Post-print

Winter, J. S. (2008). "Emerging policy problems related to ubiquitous computing: Negotiating stakeholders' visions of the future." Knowledge, Technology \& Policy, 21, 191-203. doi:10.1007/s12130-008-9058-4. problems may quickly evolve into crises, particularly those that exhibit links to many other problems. For effective action to take place, emerging problems must be identified early in their development, while there is still adequate time to address them and they may require fewer resources to manage.

Observation of between-group differences also revealed that, in a society where technological development is increasingly based upon the manufacture and control of risk, nonspecialists may feel especially out of the loop in deciding which risks are acceptable. This concern was expressed in the context of technology policy and planning decisions at local and state levels, and also in the design and control of information and communication technologies. This indicates that, in an increasingly complex technical environment, non-specialists may feel some alienation from the process of decision making about what constitutes acceptable risk in the context of UNC and thus greater consternation about the future. To more actively involve citizens in the planning process, the State of Hawaii has recently sought to engage a broader community in the planning process through the Hawaii 2050 Sustainability Plan and related efforts (http://hawaii2050.org/).

\section{Conclusion}

Future mobile and Ubiquitous Computing environments are likely to offer myriad opportunities and threats. Many of these transitions will be embraced by some segments of society and reviled by others, particularly those issues related to human evolution, including integration of human and machine intelligences. As such, these developments are likely sources of future social and political conflict. Participatory foresight activities enable broad public discussion, education, and insight into these emerging issues, ensuring that technological 
Post-print

Winter, J. S. (2008). "Emerging policy problems related to ubiquitous computing: Negotiating stakeholders' visions of the future." Knowledge, Technology \& Policy, 21, 191-203. doi:10.1007/s12130-008-9058-4. developments more closely reflect broad community values and goals. Pinpointing areas where divergence occurs for future analysis may be an effective strategy for detecting potential emerging problems long before they become crises. The creation, exploration, and testing of a variety of "visions about the future" will aid in the reduction of uncertainty and enhance the social negotiation of multiple perspectives to guide technological development. 
Post-print

Winter, J. S. (2008). "Emerging policy problems related to ubiquitous computing: Negotiating stakeholders' visions of the future." Knowledge, Technology \& Policy, 21, 191-203. doi:10.1007/s12130-008-9058-4.

\section{References}

Abowd, G.D., Ebling, M., Hunt, G., Lei, H., \& Gellersen, H.-W. (2002). Context-aware computing. IEEE Pervasive Computing, 1(3), 22-23.

Andersen, I.-E., \& Jaeger, B. (1999). Scenario workshops and consensus conferences: Towards more democratic decision-making, Science and Public Policy, 26 (5), 331-340.

Beck, U. (1998). Politics of Risk Society. In J. Frankind (Ed.), The Politics of Risk Society (pp. 9-22). Cambridge, UK: Polity Press.

Bell, G. (2006). The Age of the Thumb: A cultural reading of mobile technologies from Asia. Knowledge, Technology \& Policy, 19(2), 41-57.

Bell, G., \& Dourish, P. (2006). Yesterday's tommorows: Notes on Ubiquitous Computing's dominant vision. Personal and Ubiquitous Computing, 11(2), 133-143.

Bell, W. (1996b). What do we mean by futures studies? In: R. Slaughter (Ed.), New thinking for a new millennium, (pp.3-25). New York: Routledge.

Bickmore, T., \& Picard, R. (2005). Establishing and maintaining long-term human-computer relationships. ACM Transactions on Computer-Human Interaction, 12(2), 293-327.

Castells, M., Fernández-Ardèvol, M., Qiu, J.L., \& Sey, A. (2006). Mobile communication and society: A global perspective. Cambridge, MA: The MIT Press.

Cerf, V.G. (1999). In the belly of the Net. In P. J. Denning (Ed.), Talking back to the machine: Computers and human aspiration (pp. 89-98). New York: Copernicus.

Creswell, J.W. (1998). Qualitative inquiry and research design: choosing among five traditions. Thousand Oaks, CA: Sage.

Dator, J. (1996). Futures studies as applied knowledge. In: R. A. Slaughter (Ed.), New thinking for a new millennium, (pp. 105-115). New York: Routledge.

Dator, J. (1997). As if I virtually said this to Pepsi executives during a futures discussion at their headquarters. Retrieved March 3, 2007, from http://www.futures.hawaii.edu/dator/ artificiality/pepsi.html.

Dertouzos, M.L. (1999). The future of computing. Scientific American, 281(2), 52-55.

Dourish, P. (2001). Where the action is: The foundations of embodies interaction. Cambridge, MA: MIT Press. 
Post-print

Winter, J. S. (2008). "Emerging policy problems related to ubiquitous computing: Negotiating stakeholders' visions of the future." Knowledge, Technology \& Policy, 21, 191-203. doi:10.1007/s12130-008-9058-4. Fogg, B.J. (1998). Captology: The study of computers as persuasive technologies. In: Proceedings of the CHI 98 Summary Conference: Human Factors in Computing Systems: 385. New York: Association for Computing Machinery.

Giddens, A. (1990). The consequences of modernity. Stanford: Stanford University Press.

Glenn, J.C. (1994). Participatory methods. In: J. C. Glenn \& T. J. Gordon (Eds.), Futures research methodology (Millennium Project): American Council for the United Nations University, Millennium Project.

Glotz, P., \& Bertschi, S. (2006). People, mobiles and society: Concluding insights from an international expert survey. Knowledge, Technology \& Policy, 19(2), 69-92.

Helmer, O. (1983). Looking forward: A guide to futures research. Beverly Hills: Sage Publications.

International Telecommunications Union. (2005). Privacy and ubiquitous network societies. Geneva: International Telecommunications Union. Retrieved July 2, 2006, from http://www.itu.int/osg/spu/ni/ubiquitous/Papers/ Privacy\%20background\%20paper.pdf

Katz, J.E. (2006a). Magic in the air: Mobile communication and the transformation of social life. New Brunswick: Transaction.

Katz, J.E. (2006b). Mobile communication and the transformation of daily life: The next phase of research on mobile. Knowledge, Technology \& Policy, 19(1), 63-71.

Kurzweil, R. (1999). The age of spiritual machines: When computers exceed human intelligence. New York: Viking.

Ling, R. (2004). The mobile connection: The cell phone's impact on society. Amsterdam: Morgan Kaufman.

Maes, P. (1999). Very personal computers. In P. J. Denning (Ed.), Talking back to the machine: Computers and human aspiration (pp. 37-44). New York: Copernicus.

Massachusetts Institute of Technology. Computer Science and Artificial Intelligence Laboratory. (2004). MIT Project Oxygen: project overview. Retrieved January 22, 2006 from http://oxygen.lcs.mit.edu/Overview.html

Molitor, G. (1977). How to anticipate public policy changes. S.A.M. Advanced Management Journal, Summer 1977, 4-13.

Nass, C. et al. (1995). Can computer personalities be human personalities? International Journal of Human-Computer Studies, 43(2): 223-239. 
Post-print

Winter, J. S. (2008). "Emerging policy problems related to ubiquitous computing: Negotiating stakeholders' visions of the future." Knowledge, Technology \& Policy, 21, 191-203. doi:10.1007/s12130-008-9058-4. Organisation for Economic Co-operation and Development (OECD). (2003). Promises and problems of e-democracy: Challenges of online citizen engagement. Paris: OECD.

Picard, R., Wexelblat, A., \& Nass, C. (2002). Future interfaces: social and emotional. Conference on Human Factors in Computing Systems, pp. 698-699. Minneapolis: Association for Computing Machinery.

Polak, F. (1961). The image of the future: enlightening the past, orientating the present, forecasting the future. New York: Oceana.

Renfro, W. L. (1994). Issues management in strategic planning. Westport, CT: Quorum Books.

Ridley, K. (27 June, 2007). Global mobile phone use to hit record 3.25 billion. Retrieved July 2, 2007, from http:/www.reuters.com/article/companyNewsAndPR/ idUSL2712199720070627

Salmon, G. (2000). E-Moderating: the key to teaching and learning online. London: Kogan Page.

Sclove, R.E. (1995). Democracy and technology. New York: Guilford Press.

Sclove, R.E. (1996). Town meetings on technology. Technology Review, 1996 (7).

Schwartz, P. (1991). The art of the long view: Planning for the future in an uncertain world. New York: Doubleday.

Siagri, R. (2007). Pervasive computers and the GRID: the birth of a computational exoskeleton for augmented reality. Foundations of Software Engineering: Proceedings of the 6th Joint Meeting of the European Software Engineering Conference, pp. 1-4. Dubrovnik, Croatia: Association for Computing Machinery.

Starner, T.E. (2003). Attention, memory, and wearable interfaces. IEEE Pervasive Computing, $1(4), 88-91$.

Stone, P. J. (1997). Thematic text analysis: new agendas for analyzing text content. In: C. Roberts (Ed.), Text analysis for the social sciences: Methods for drawing statistical inferences from texts and transcripts, (pp. 35-54). Mahwah, NJ: Lawrence Erlbaum.

Stone, P. J., Dunphy, D. C. \& Bernstein, A. (1966). The analysis of product image. In: P. J. Stone et al. (Eds.), The general inquirer: A computer approach to content analysis. Cambridge, MA: MIT Press.

Suchman, L. (1987). Plans and situated actions: The problem of human-machine communication. Cambridge, UK: Cambridge University Press. 
Post-print

Winter, J. S. (2008). "Emerging policy problems related to ubiquitous computing: Negotiating stakeholders' visions of the future." Knowledge, Technology \& Policy, 21, 191-203. doi:10.1007/s12130-008-9058-4.

Tennenhouse, D. (2000). Proactive computing. Communications of the ACM, 43(5): 43-5.

Tscheligi, M., \& Reitberger, W. (2007). Persuasion as an ingredient of societal interfaces. Interactions 14(5), 41-43.

Union of International Associations. (2001). Section 1.2 - Significance: constraints on a problem-focused approach; and Section 2.3 - Criteria: definitions. Encyclopedia of world problems and human potential. Brussels: Union of International Associations. Retrieved August 8, 2007 from http://www.uia.org/uiapubs/pubency.htm

Wedemeyer, D. J., Ono, R., \& Winter, J. (2001). Describing and reducing global telecommunications problems. Pacific Telecommunications Council Conference Proceedings. Honolulu: Pacific Telecommunications Council.

Weiser, M. (1993). Some computer science issues in Ubiquitous Computing. Communications of the $A C M, 36(7), 75-84$.

Weiser, M., \& Brown, J.S. (1997). The coming age of calm technology. In R. Metcalfe \& P. Denning (Eds.), Beyond calculation: The next fifty years of computing (pp. 75-85). New York: Springer-Verlag.

Winter, J.S. (2006). Increased public involvement in technology policy: Focus on the pervasive computing environment. ACM Computers and Society, 36(1).

Zambonelli, F., Gleizes, M-P., Mamei, M., \& Tolksdorf, R. (2005). Spray computers: Explorations in self-organization. Pervasive and Mobile Computing, 1(1), 1-20. 
Post-print

Winter, J. S. (2008). "Emerging policy problems related to ubiquitous computing: Negotiating stakeholders' visions of the future." Knowledge, Technology \& Policy, 21, 191-203. doi:10.1007/s12130-008-9058-4.

\section{Table 1. Problem Statements in the Psychological Domain}

\begin{tabular}{|c|c|c|}
\hline Item & Problem Statement & Group \\
\hline Ps01 & $\begin{array}{l}\text { People will become so immersed in virtual realities (computer simulations of real or } \\
\text { imagined environments) that the "real world" will be neglected }\end{array}$ & $\mathrm{N}$ \\
\hline Ps02 & $\begin{array}{l}\text { Longer life spans will make it psychologically stressful for people to deal with the rapid } \\
\text { pace of change and the loss of familiar ways of being }\end{array}$ & $\mathrm{N}$ \\
\hline Ps03 & $\begin{array}{l}\text { Always available information sources will make "information overload" (too much } \\
\text { information to process) even more acute }\end{array}$ & Both \\
\hline Ps04 & $\begin{array}{l}\text { Technological developments that minimize interaction between humans will have } \\
\text { detrimental effects on people's social skills and welfare (e.g. difficulty communicating, } \\
\text { isolation) }\end{array}$ & Both \\
\hline Ps05 & $\begin{array}{l}\text { Many people will become more guarded or "disconnected" as a way of self-preservation } \\
\text { due to pervasive surveillance devices }\end{array}$ & $\mathrm{N}$ \\
\hline Ps06 & $\begin{array}{l}\text { Invasive use of technology enabling physical detection of human emotion or higher level } \\
\text { thought processes will result in an invasion of privacy }\end{array}$ & $\mathrm{N}$ \\
\hline Ps07 & $\begin{array}{l}\text { The pervasiveness of miniature surveillance devices present throughout the environment } \\
\text { will prevent the average person from knowing what kind of personal data is being collected } \\
\text { and with whom it is being shared }\end{array}$ & Both \\
\hline Ps08 & $\begin{array}{l}\text { With cloning, the concern for the welfare of artificial life, and the quest for extending life } \\
\text { beyond natural limits, there will be less emphasis on spirituality or the sacredness of life }\end{array}$ & $\mathrm{N}$ \\
\hline Ps09 & $\begin{array}{l}\text { Some people will become "less than human" due to biological or mechanical } \\
\text { enhancements }\end{array}$ & $\mathrm{N}$ \\
\hline Ps10 & $\begin{array}{l}\text { Intelligent computers and/or biological enhancements will anticipate our choices or } \\
\text { become part of us, making it difficult to live spontaneously and have free will }\end{array}$ & $\mathrm{N}$ \\
\hline Ps11 & $\begin{array}{l}\text { Psychological tension will arise due to individuals' inability to distinguish between human } \\
\text { and computer interactions (e.g. some computers may appear so intelligent that it is } \\
\text { difficult to tell the difference) }\end{array}$ & $S$ \\
\hline Ps12 & $\begin{array}{l}\text { Autonomous, intelligent computers will operate on our behalf without adequate human } \\
\text { oversight }\end{array}$ & $S$ \\
\hline Ps13 & $\begin{array}{l}\text { Due to technology-mediated communication and electronic surveillance it will be } \\
\text { increasingly difficult to establish strong individual identities }\end{array}$ & $S$ \\
\hline Ps14 & $\begin{array}{l}\text { There will be a lack of personal accountability and responsibility for one's actions due to } \\
\text { increased automation and/or biological or mechanical augmentation of humans }\end{array}$ & $N$ \\
\hline
\end{tabular}


Post-print

Winter, J. S. (2008). "Emerging policy problems related to ubiquitous computing: Negotiating stakeholders' visions of the future." Knowledge, Technology \& Policy, 21, 191-203. doi:10.1007/s12130-008-9058-4.

Table 2. Mann-Whitney U Test, Psychological Domain

\begin{tabular}{|c|c|c|c|c|c|}
\hline Item & Ms & $\mathbf{M N}_{\mathrm{N}}$ & U & $\mathbf{Z}$ & \begin{tabular}{|} 
2-tailed Sig. \\
$(p<.05)$
\end{tabular} \\
\hline Ps01 & 1.41 & 2.02 & 1392.000 & -2.568 & $.010^{*}$ \\
\hline Ps02 & 1.52 & 1.75 & 1689.000 & -1.027 & .305 \\
\hline Ps03 & 1.72 & 1.82 & 1808.500 & -.403 & .687 \\
\hline Ps04 & 2.02 & 2.81 & 1186.500 & -3.527 & $.000^{*}$ \\
\hline Ps05 & 2.14 & 2.25 & 1765.000 & -.463 & .643 \\
\hline Ps06 & 2.48 & 3.00 & 1431.000 & -2.394 & $.017^{*}$ \\
\hline Ps07 & 2.84 & 3.11 & 1641.000 & -1.314 & .189 \\
\hline Ps08 & 1.47 & 2.40 & 1161.500 & -3.743 & $.000^{*}$ \\
\hline Ps09 & 1.04 & 1.68 & 1327.000 & -2.790 & $.005^{*}$ \\
\hline Ps10 & 1.22 & 2.00 & 1235.500 & -3.261 & $.001^{*}$ \\
\hline Ps11 & 1.31 & 2.03 & 1260.500 & -3.133 & $.002^{*}$ \\
\hline Ps12 & 1.81 & 2.34 & 1460.500 & -2.204 & $.027^{*}$ \\
\hline Ps13 & 1.22 & 2.12 & 1153.000 & -3.806 & $.000^{*}$ \\
\hline Ps14 & 1.77 & 2.43 & 1363.500 & -2.569 & $.010^{*}$ \\
\hline
\end{tabular}

$\mathrm{S}=$ Specialists, $\mathrm{N}=$ Non-Specialists 
Post-print

Winter, J. S. (2008). "Emerging policy problems related to ubiquitous computing: Negotiating stakeholders' visions of the future." Knowledge, Technology \& Policy, 21, 191-203. doi:10.1007/s12130-008-9058-4.

Figure 1. Mean Scores of Problem Importance, Psychological Domain

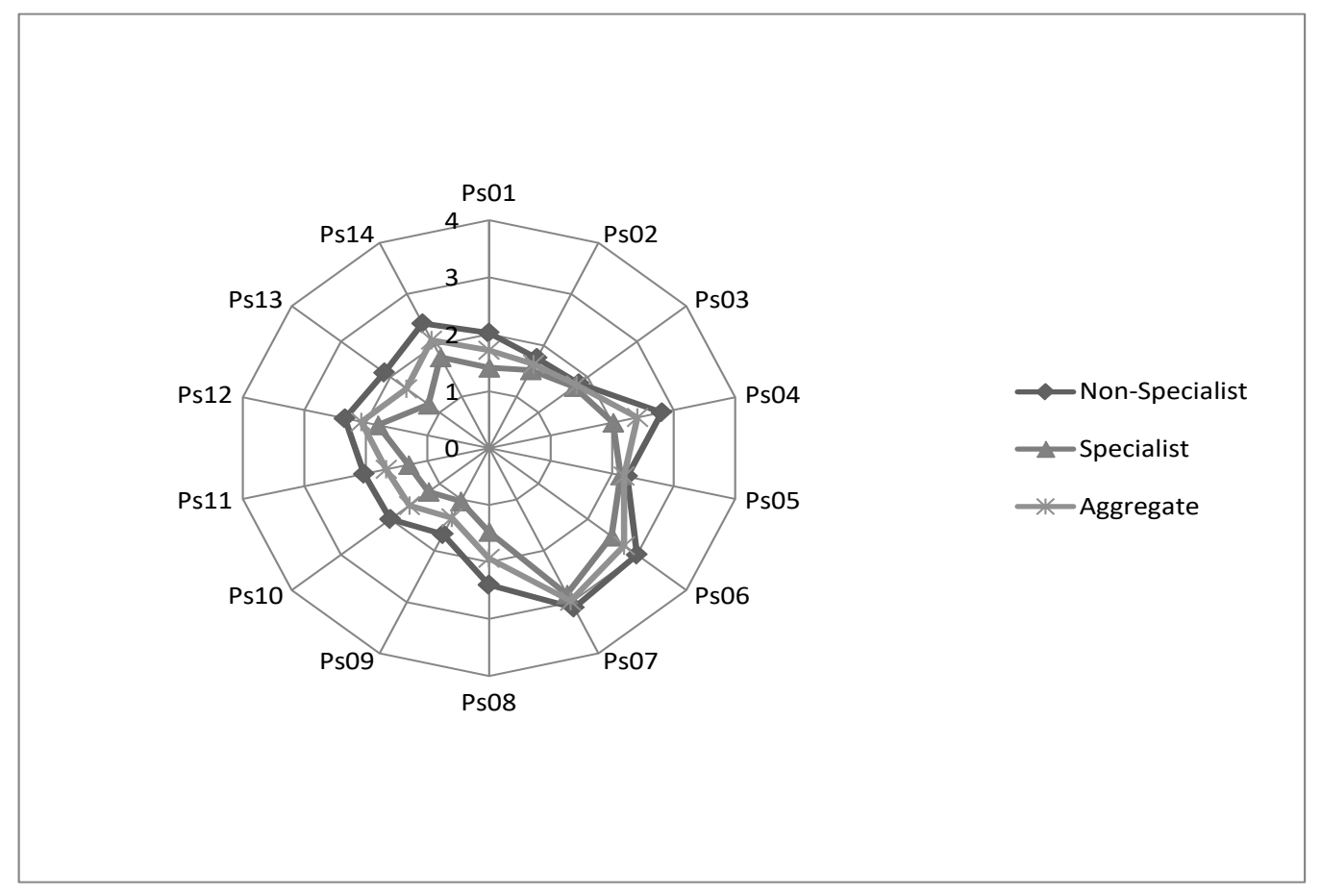

It should be noted that policy and planning activities are inherently futures-oriented and that the many ways in which it might develop, must remain in focus. 